\title{
Preface
}

\author{
Qide Han*
}

\section{New challenges in medicine}

https://doi.org/10.1515/mr-2021-0033

I feel honored to be part of the launch of Medical Review $(M R)$ and witness this milestone moment with colleagues around the world. My personal involvement with this journal dates back to an event in July 2019 that marked the 60th anniversary of the Journal of Peking University (Health Sciences). It was during that event that I proposed that Peking University Health Science Center should learn from the success of the Chinese Academy of Sciences in creating National Science Review (NSR), and launch a journal devoted to reviews in medical sciences. My vision for the proposed journal was one that featured primarily China-based studies but was easily accessible to an international readership. Under the strong support of the Chinese Ministry of Education among other competent authorities, that vision-to my great pleasure-becomes a reality.

For better or for worse, we live in an era of profound changes. In such dynamic times, the world needs to come together as a community of shared future and create stronger synergy in its response to global challenges and in its pursuit of peace and development. The urgency of shifting to this mindset of oneness in approaching human endeavors has become even more vivid-at least on the health front-during the COVID-19 pandemic.

The pandemic has also underscored the importance of medical sciences. However, medical sciences, too, is undergoing a paradigm shift, as manifest in the rapid development of molecular medicine and the extensive application of information technologies such as the internet, big data and artificial intelligence. It is therefore imperative for the medical community-especially the medical community in China-to strengthen exchange by creating more journals that are capable of presenting high-quality studies in a timely and user-friendly manner.

The quality of scientific journals in a country says very much about the strengths and concertedness of its scientific community. Proceeding from this understanding, President Xi Jinping emphasized last year in his talks with scientists that long-term efforts should be made to nurture a number of first-class journals and platforms for domestic and international academic exchange. Yet despite progress in recent years, the quantity and quality of domestic journals still fall short of both the strategy to build China into a science and technology giant and the expectation of the Chinese scientific community.

Given the backdrop of the COVID-19 pandemic and the thirst of China for high-quality journals, the $M R$ is launched at the best timing. And it is in good hands, too. Peking University, with its academic strengths, influence and network, journal running experience, medical research, and prominence in the Double First-Class initiative, will have much to offer.

With support from the Peking University, leadership by Editor-in-Chief Dr. Zhan Qimin, and contributions from colleagues around the world, the $M R$ will, as I am convinced, be a journal for innovative people to keep pushing the academic frontier into the unknown, advancing medicine and health in both China and the world at large. 